\title{
Potassium single cation ionic liquid electrolyte for potassium-ion batteries
}

\author{
$\operatorname{AUTHOR}(S):$ \\ Yamamoto, Hiroki; Chen, Chih-Yao; Kubota, Keigo; \\ Matsumoto, Kazuhiko; Hagiwara, Rika
}

\section{CITATION:}

Yamamoto, Hiroki ... [et al]. Potassium single cation ionic liquid electrolyte for potassiumion batteries. The Journal of Physical Chemistry B 2020, 124(29): 6341-6347

\section{ISSUE DATE:}

2020-07-23

URL:

http://hdl.handle.net/2433/260566

\section{RIGHT:}

This document is the Accepted Manuscript version of a Published Work that appeared in final form in The Journal of Physical Chemistry B, copyright (C) American Chemical Society after peer review and technical editing by the publisher. To access the final edited and published work see https://doi.org/10.1021/acs.jpcb.0c03272.; The full-text file will be made open to the public on 29 June 2021 in accordance with publisher's 'Terms and Conditions for Self-Archiving'.; Z の論文は出版社版でありません。引用の際には出版社版をご確認ご利用ください。；This is not the published version. Please cite only the published version. 


\section{Potassium Single Cation Ionic Liquid Electrolyte for}

\section{Potassium-Ion Batteries}

Hiroki Yamamoto, ${ }^{a, b}$ Chih-Yao Chen,${ }^{a}$ Keigo Kubota,${ }^{a, b *}$ Kazuhiko Matsumoto, ${ }^{a, b *}$

Rika Hagiwara ${ }^{a, b}$

a) AIST-Kyoto University Chemical Energy Materials Open Innovation Laboratory (ChEMOIL), National Institute of Advanced Industrial Science and Technology (AIST), Sakyo-ku, Kyoto 606-8501, Japan

b) Graduate School of Energy Science, Kyoto University, Yoshida, Sakyo-ku, Kyoto 606-8501, Japan 


\section{ABSTRACT}

Potassium-ion batteries (PIBs) are a promising post-lithium-ion battery (LIB) as their resources are abundant and low-cost, and may have a higher voltage than LIBs. However, the high operating voltage and extremely high reactivity of potassium metal require a chemically safe electrolyte with oxidative and reductive stabilities. In this study, potassium single cation ionic liquid (K-SCIL), which contains only $\mathrm{K}^{+}$as a cationic species and have high electrochemical stability, low flammability, and low vapor pressure, is developed as an electrolyte for PIBs. The mixture of $\begin{array}{llll}\text { potassium } & \text { bis(fluorosulfonyl)amide } \quad(\mathrm{K}[\mathrm{FSA}]) & \text { and } & \text { potassium }\end{array}$ (fluorosulfonyl)(trifluoromethylsulfonyl)amide (K[FTA]) at a molar ratio of 55:45 had the lowest melting point of $67^{\circ} \mathrm{C}$. The $\mathrm{K}^{+}$concentration in this $\mathrm{K}-\mathrm{SCIL}$ is high $\left(8.5 \mathrm{~mol} \mathrm{dm}{ }^{-3}\right.$ at $\left.90{ }^{\circ} \mathrm{C}\right)$ due to the absence of solvents and bulky organic cations. In addition, the electrochemical window is as wide as $5.6 \mathrm{~V}$, which enables the construction of PIBs with a high energy density. A high current density can be achieved with this K-SCIL owing to the absence of $\mathrm{K}^{+}$concentration gradient. The electrolyte was successfully used with a graphite negative electrode, enabling the reversible intercalation/deintercalation of $\mathrm{K}^{+}$, as confirmed by X-ray diffraction. 


\section{INTRODUCTION}

Alkali-metal ion batteries, in which alkali metal ions migrate between positive and negative electrodes, have been extensively studied due to their high voltage and capacity. Especially, lithium-ion batteries (LIBs) have been widely used and are predominant in the small electronic devices and even electronic vehicles. ${ }^{1-2}$ However, LIBs are expensive, and the scarcity and uneven distribution of lithium resources could limit their continuously expanding production and prevent their use in large-scale or stationary applications. ${ }^{3}$

Demand for post-LIBs, i.e., more sustainable energy storage systems that utilize abundant elements to achieve cost-effectiveness, is increasing. Recently, potassium-ion batteries (PIBs) have attracted tremendous attention as a post-LIB due to the low cost of the widespread potassium resources $\left(2.1 \mathrm{wt} \%\right.$ in the Earth's crust) ${ }^{4-8}$ In addition, PIBs are expected to achieve higher voltage than LIBs as the redox potential of potassium is lower than that of lithium. ${ }^{9}$ However, the safety issues associated with potassium metal that occur during the rapid charging or overcharging of a PIB are more profound, as potassium metal is much more reactive with oxygen and moisture than lithium metal. Thus, exploring safe battery materials with good electrochemical performance is vital for the development of PIBs.

PIBs were first studied in 2004 with a Prussian blue cathode and an organic solvent-based electrolyte composed of an organic solvent and $\mathrm{KBF}_{4} \cdot{ }^{10}$ In most previous studies, the design of the electrolyte for PIBs has been similar to that for LIBs. For example, potassium salts, which shuttle between electrodes, typically contain perfluoroanions such as $\mathrm{KPF}_{6}$ and $\mathrm{KBF}_{4}$ due to their high oxidative resistance. Electrolytes based on organic solvents, ${ }^{11}$ room-temperature ionic liquid (RTIL) containing organic cations, ${ }^{12-13}$ and polymers ${ }^{14}$ have also been reported. 
Highly concentrated electrolytes with organic solvents have attracted interest for use in alkali metal ion batteries due to their unique properties, including high oxidation resistance attributed to the more reduced solvent molecules that have no direct coulombic interactions with ions and low oxidation stability. ${ }^{14-23}$ It is interesting to investigate how these properties change if the concentration of alkali metal ions in electrolytes are increased even further. However, to our knowledge, potassium salts are less soluble in the abovementioned solvents than lithium salts, which makes investigation at high $\mathrm{K}^{+}$concentrations difficult. ${ }^{15-19}$

Against this background, we have investigated an IL electrolyte composed of only potassium cation as cationic species combined with counter-anions, which is referred to as "potassium-single cation ionic liquid (K-SCIL)" electrolytes. A similar concept for LIBs was proposed in previous studies, targeting the improvement of lithium cation transport. ${ }^{24-27}$ Unlike typical RTIL electrolytes or traditional high-temperature molten salts, K-SCIL electrolytes do not contain extra cationic species. Thus, the K-SCIL electrolytes can be regarded as the extreme of the highly concentrated electrolytes in terms of molar concentration of potassium salt. Moreover, similar to RTIL electrolytes, K-SCIL electrolytes have low vapor pressure and low flammability as they contain no organic solvent and thus they are attractive in practical battery applications. In this study, we aimed to develop PIBs using low-melting K-SCIL electrolytes, and their fundamental thermal, physicochemical properties, and electrochemical stability were investigated. Reversible chargedischarge was performed for a graphite electrode placed in the electrolyte, confirming the feasibility of this new class of electrolyte for PIBs. 


\section{EXPERIMENTAL SECTION}

Potassium bis(fluorosulfonyl)amide (K[FSA]; Tokyo Chemical Industry, purity >95\%), potassium (fluorosulfonyl)(trifluorosulfonyl)amide (K[FTA]; Tokyo Chemical Industry, purity $>95 \%$ ), and $N$-methyl- $N$-propylpyrrolidinium bis(fluorosulfonyl)amide ([C ${ }_{3} \mathrm{C}_{1}$ pyrr][FSA]; Kanto

Chemical, purity $>99.9 \%$ ) were dried at $80{ }^{\circ} \mathrm{C}$ under pressure of 1 Pa prior to use. Mixtures of $\mathrm{K}[\mathrm{FSA}]$ and $\mathrm{K}[\mathrm{FTA}]$ were then prepared in a dry chamber (DAIKIN, HRG-50AR, dew point $<-50{ }^{\circ} \mathrm{C}$ ) by mixing the two powders and grinding them. The $\mathrm{K}_{0.2}\left[\mathrm{C}_{3} \mathrm{C}_{1} \text { pyrr }\right]_{0.8}[\mathrm{FSA}]$ RTIL was prepared by mixing $\mathrm{K}[\mathrm{FSA}]$ and $\left[\mathrm{C}_{3} \mathrm{C}_{1}\right.$ pyrr][FSA] in a molar ratio of 20 and $80 .{ }^{12}$

Thermal transition temperatures were measured using a differential scanning calorimeter (DSC; Hitachi High-Technologies, DSC220) under flowing nitrogen gas at scan rates of either $10^{\circ} \mathrm{C} \cdot \mathrm{min}^{-1}$ or $2^{\circ} \mathrm{C} \cdot \mathrm{min}^{-1}$. The DSC samples were sealed in an aluminum pan in the dry chamber to avoid exposure to the air.

The densities of the samples were obtained using a $5-\mathrm{mL}$ volumetric cylinder by weighing a sample and visually confirming its volume during heating. The viscosities of the samples were measured using an electro-magnetically spinning viscometer (Kyoto Electronics Manufacturing Co., Ltd., EMS-100). The samples were sealed in glass tubes in the dry chamber with a spherical Al probe, and any bubbles were removed, followed by heating and melting. The specific conductivities of the samples were measured by $\mathrm{AC}$ impedance spectroscopy with an $\mathrm{AC}$ perturbation of $10 \mathrm{mV}$ using an electrochemical analyzer (HOKUTO DENKO, HZ-Pro). The sample was sealed in a cell with two Pt black electrodes (RADIOMETER ANALYTICAL, the cell constant was obtained by measuring the conductivity of the $\mathrm{KCl}$ saturated standard solution using the cell), and the entire cell was placed in the dry chamber. 
Electrochemical measurements were conducted using a stainless-steel cell (Hohsen Corp., HS2) in a two-electrode configuration with the potassium metal counter electrode with the aid of the electrochemical analyzer. A glass separator (Nippon Sheet Glass, TGP010, thickness of $100 \mu \mathrm{m}$ ) soaked in the K-SCIL electrolyte was used, and the cells were assembled in an argon-filled glove box (UNICO, UL-1800AA-KIZ, $\left[\mathrm{H}_{2} \mathrm{O}\right]$ and $\left[\mathrm{O}_{2}\right]$ : $<1 \mathrm{ppm}$ ) to prevent any exposure to moisture and oxygen. Electrochemical window of the K[FSA $]_{0.55}[\text { FTA }]_{0.45}$ SCIL was determined by the cyclic voltammetry at $90^{\circ} \mathrm{C}$ using an aluminum and a platinum plate working electrodes. Limiting current density of the $\mathrm{K}[\mathrm{FSA}]_{0.55}[\mathrm{FTA}]_{0.45} \mathrm{SCIL}$ and $\mathrm{K}_{0.2}\left[\mathrm{C}_{3} \mathrm{C}_{1} \text { pyrr }\right]_{0.8}[\mathrm{FSA}]$ RTIL was determined on an aluminum plate working electrode by galvanostatic polarization at $80 \mathrm{~mA} \cdot \mathrm{cm}^{-2}$ at $90{ }^{\circ} \mathrm{C}$. Charge-discharge tests were conducted at $80{ }^{\circ} \mathrm{C}$ on a graphite electrode composed of natural graphite powder (SNO-10, SEC Carbon Ltd., mean diameter of $10 \mu \mathrm{m}$ ) and polyvinylidene fluoride (PVDF) (KUREHA) binder (graphite:PVDF $=80: 20$ in the weight ratio) on a copper current collector. Powder X-ray diffraction (XRD) patterns were obtained using an X-ray diffractometer (Rigaku Corp., SmartLab, $\mathrm{Cu} \mathrm{K \alpha}$ radiation, $40 \mathrm{kV}, 30 \mathrm{~mA}$ ) to investigate the intercalation/deintercalation of $\mathrm{K}^{+}$into/from graphite, respectively. The graphite electrode for XRD analysis was charged by a constant current/constant voltage mode ( $0.5 \mathrm{C}$ (cutoff: $2.5-0.1 \mathrm{~V})$ / $0.1 \mathrm{~V}$ (cutoff: $0.1 \mathrm{C}$ ). The samples were then loaded in an airtight cell with beryllium windows under argon atmosphere. 


\section{RESULTS AND DISCUSSION}

3.1. Thermal Property. In order to use the K-SCIL electrolytes for PIBs, lowering of melting point is preferred for handling and material availability, and mixing of two $\mathrm{K}^{+}$salts was examined here. In a preliminary screening for the binary mixture of nine K salts (50:50 in mol), the K[FSA]K[FTA ] binary system provided the lowest melting point, owing to the property of $\mathrm{FSA}^{-}$and $\mathrm{FTA}^{-}$ anions to give low melting points, ${ }^{27,28}$ and thus this system was selected for further investigation of K-SCIL for PIB (see Table S1 for the summary of preliminary screening).

Figure 1 shows a phase diagram of the K[FSA]-K[FTA] system at intervals of 10 or $5 \mathrm{~mol} \%$ within the low-melting range of interest (melting points of neat $\mathrm{K}[\mathrm{FSA}]$ and $\mathrm{K}[\mathrm{FTA}]$ are $102{ }^{\circ} \mathrm{C}$ and $101{ }^{\circ} \mathrm{C}$, respectively). The solidus line was determined from the onset of the endothermic peak in the DSC continuous curve at a rate of $10{ }^{\circ} \mathrm{C} \min ^{-1}$ (Figure S1a). The liquidus line was determined from the smallest endothermic peak in the DSC step curve at a step of $2{ }^{\circ} \mathrm{C}$ (Figure S1b). Even so it was difficult to determine the melting point precisely in this system, as the liquid phase of the mixtures was not crystallized rapidly and exhibited glass transition instead, which is similar to that often observed for some organic RTILs. ${ }^{29}$ In addition, this system exhibited multiple thermal transitions depending on the heating and cooling cycles. The occurrence of these phenomena is attributed to the presence of some meta-stable solid phases based on the polymorphism of the perfluorosulfonylamides. ${ }^{30,31}$ The highest melting point, which corresponds to the melting of the most stable solid phase measured during the first heating in the DSC measurement of the prepared powder sample (Figure S2), is taken as the melting point and plotted in Figure 1. This system is a simple eutectic system, where the melting points of single salts directly reduce to the lowest melting point of $67^{\circ} \mathrm{C}$ at a $\mathrm{K}[\mathrm{FSA}]: \mathrm{K}[\mathrm{FTA}]$ molar ratio of 55:45 $\left(\mathrm{K}[\mathrm{FSA}]_{0.55}[\mathrm{FTA}]_{0.45}\right)$. This composition was identified as the eutectic point in this system within 
an experimental error of $5 \mathrm{~mol} \%$ and regarded to be the most suitable as the K-SCIL for PIB that can be used near room temperature without any additional organic solvent, RTIL, and other alkali metal salt.

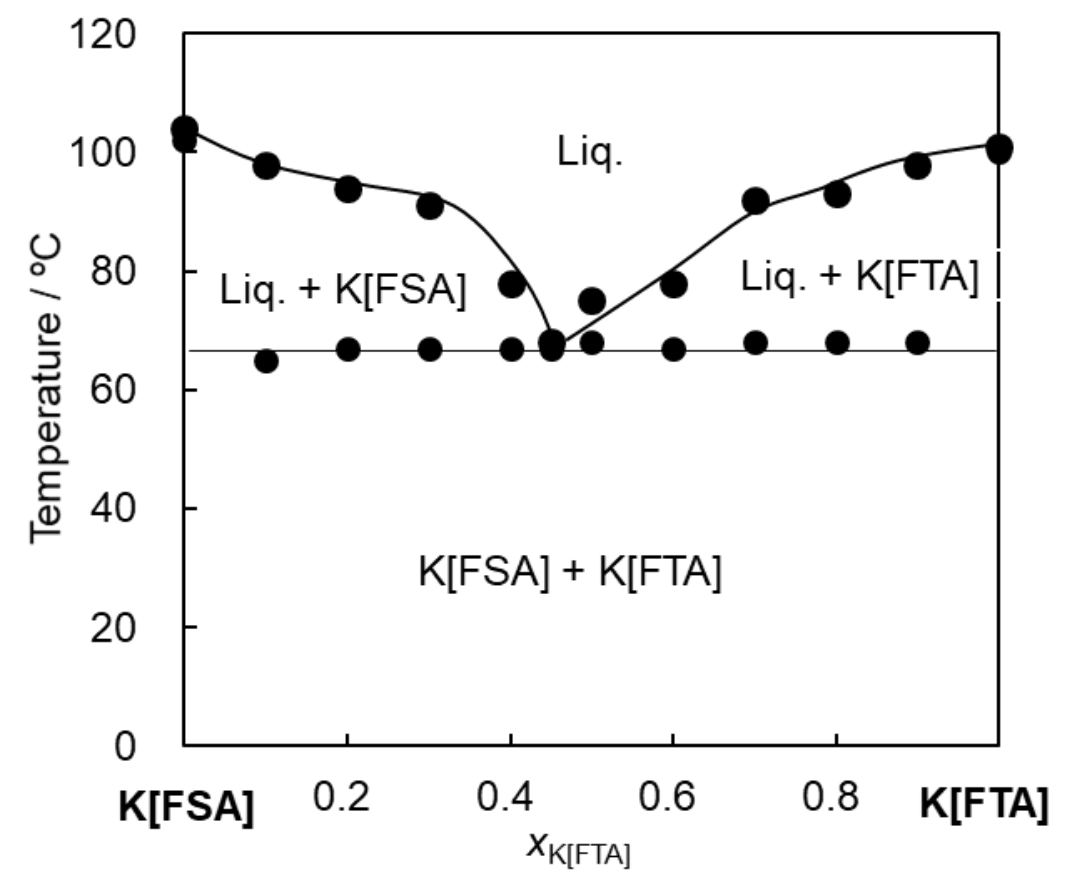

Figure 1. Phase diagram of the K[FSA]-K[FTA] binary system determined by DSC analysis. The abbreviations Liq. and $X_{\mathrm{K}[\mathrm{FTA}]}$ denote the liquid phase and molar ratio of K[FTA] in this system.

3.2. Viscosity. The viscosity $(\eta)$ of the $\mathrm{K}[\mathrm{FSA}]_{0.55}[\mathrm{FTA}]_{0.45} \mathrm{SCIL}$ is shown in Figure 2 together with those of other K-SCIL (so-called high-temperature molten salts with $\mathrm{K}^{+}$are also included as K-SCIL) and RTIL. Owing to the reduction of the melting point, the $\mathrm{K}[\mathrm{FSA}]_{0.55}[\mathrm{FTA}]_{0.45} \mathrm{SCIL}$ was a fluid liquid in a wider range near room temperature, which is in contrast to its constituent individual salts. Its temperature dependence follows the VTF (Vogel-Tammann-Fulcher) equation as follows, which is not similar to traditional hightemperature molten salts, but closer to RTIL electrolytes containing K[FSA $]^{12}$; 


$$
\eta=A_{\eta} T^{0.5} \exp \left(B_{\eta} /\left(T-T_{0 \eta}\right)\right)
$$

where $\eta$ is the viscosity, $T$ is the absolute temperature, $A_{\eta}$ is a constant related to the viscosity at infinite temperature, $B_{\eta}$ is a constant related to the activation energy, and $T_{0 \eta}$ is the ideal glasstransition temperature (see Table S2 for the fitting parameters), which is typically lower than the glass-transition temperature $\left(T_{\mathrm{g}}\right)$, as determined by the DSC measurements.

Potassium salts, such as halides, nitrates ${ }^{32}$, and bis(trifluoromethylsulfonate)amide $\left(\mathrm{TFSA}^{-}\right)^{33}$, exhibit a reasonably low viscosity of about $10^{\circ} \mathrm{mPa} \cdot \mathrm{s}$ above $250{ }^{\circ} \mathrm{C}$. The $\mathrm{K}$ [FSA] and K[FTA] salts have a viscosity of $10^{1}-10^{2} \mathrm{mPa} \cdot \mathrm{s}$ in the range of $110-150{ }^{\circ} \mathrm{C}$, and the $\mathrm{K}[\mathrm{FSA}]_{0.55}[\mathrm{FTA}]_{0.45}$ SCIL exhibits a viscosity between them. The K[FSA $]_{0.55}[\text { FTA }]_{0.45}$ SCIL is more viscous when it is used near its eutectic temperature $\left(10^{3} \mathrm{mPa} \cdot \mathrm{s}\right)$, similar to highly concentrated organic electrolytes. ${ }^{23}$ The higher viscosity of the K[FSA $]_{0.55}[\mathrm{FTA}]_{0.45}$ SCIL is observed compared to that of the $\mathrm{K}_{0.2}\left[\mathrm{C}_{3} \mathrm{C}_{1} \text { pyrr }\right]_{0.8}[\mathrm{FSA}] \mathrm{RTIL}$, which results from the increased cation-anion Coulombic interaction based on the small $\mathrm{K}^{+}$. Among these anions, salts with larger anions exhibit higher viscosity within the same temperature range, as the long fluoroalkyl chains lead to van der Waals interactions as well as coulombic interactions between cations and anions. The viscous nature of the $\mathrm{K}[\mathrm{FSA}]_{0.55}[\mathrm{FTA}]_{0.45} \mathrm{SCIL}$ could affect its impregnation behavior for the separator and composite electrode. 


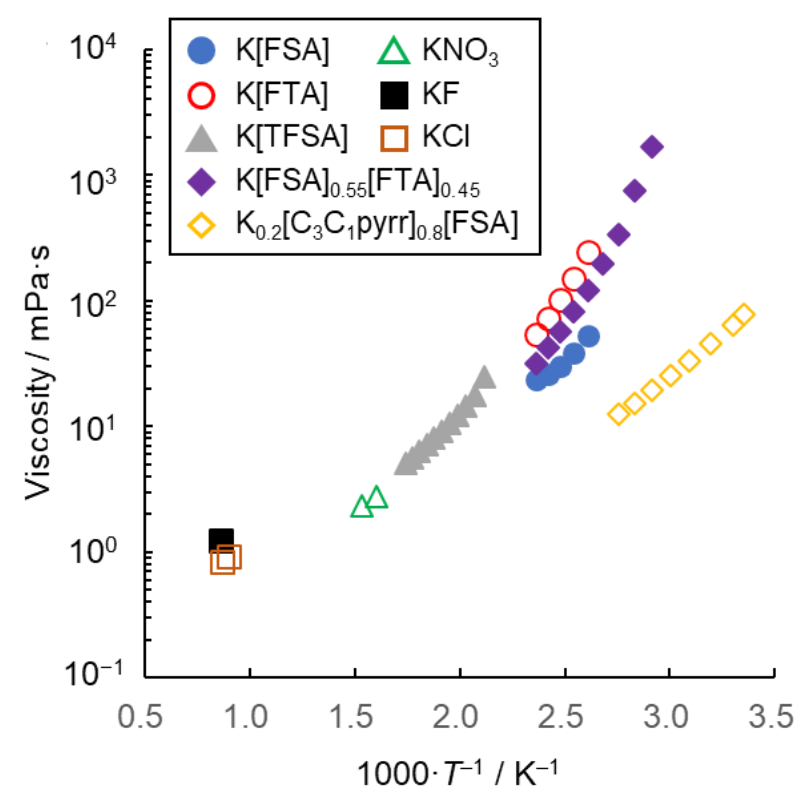

Figure 2. Arrhenius plot for the viscosity of some K-SCILs and RTIL (see references for $\mathrm{KNO}_{3}$, $\mathrm{KF}, \mathrm{KCl}$, and $\left.\mathrm{K}_{0.2}\left[\mathrm{C}_{3} \mathrm{C}_{1} \text { pyrr }\right]_{0.8}[\mathrm{FSA}]\right){ }^{12,32}$

3.3. Ionic Conductivity. Ionic conductivity $(\sigma)$, or more precisely speaking, molar ionic conductivity, is inversely related to viscosity. The ionic conductivity of the K[FSA $]_{0.55}[\mathrm{FTA}]_{0.45}$ SCIL was fitted by the VTF equation as follows:

$$
\sigma=A_{\sigma} T^{-0.5} \exp \left(-B_{\sigma} /\left(T-T_{0 \sigma}\right)\right)
$$

where $A_{\sigma}$ is a constant related to the ionic conductivity at infinite temperature, $B_{\sigma}$ is a constant related to the activation energy, and $T_{0 \sigma}$ is the ideal glass-transition temperature (see Table $\mathrm{S} 2$ for the fitting parameters). In general, organic electrolytes used in current batteries have ionic conductivities of $10^{1}-10^{2} \mathrm{mS} \cdot \mathrm{cm}^{-1}$. As shown in Figure 3, the high-temperature molten potassium salts have higher ionic conductivities than those of perfluorosulfonylamide ILs, which mainly results from the difference in temperature range. The K[FSA $]_{0.55}[\mathrm{FTA}]_{0.45}$ SCIL exhibited ionic 
conductivities less than $10^{2} \mathrm{mS} \cdot \mathrm{cm}^{-1}$ which are lower than those of typical RTIL electrolytes including $\mathrm{K}_{0.2}\left[\mathrm{C}_{3} \mathrm{C}_{1} \text { pyrr }\right]_{0.8}[\mathrm{FSA}] .{ }^{12}$ However, the Walden plot in Figure 4 indicates that the $\mathrm{K}[\mathrm{FSA}]_{0.55}[\mathrm{FTA}]_{0.45}$ SCIL possesses high conductivity despite its viscous nature, which differs from the properties of previously explored RTILs. ${ }^{34-37}$ A highly dissociated state is proposed for most of the K-SCILs as their conductivities are close to the ideal value (dashed line in Figure 4) predicted by their viscosity, and especially those for the K[FSA $]_{0.55}[\mathrm{FTA}]_{0.45}$ SCIL are above the dashed line., whereas $\mathrm{K}_{0.2}\left[\mathrm{C}_{3} \mathrm{C}_{1} \text { pyrr }\right]_{0.8}[\mathrm{FSA}] \mathrm{RTIL}$ exhibits a relatively low conductivity, in spite of its low viscosity. The high viscosity is attributed to the $\mathrm{FSA}^{-}$and $\mathrm{FTA}^{-}$anions, while the comparatively high conductivity in the K-SCIL derives from the mobility of highly concentrated $\mathrm{K}^{+}$, without generating a concentration gradient (see the next section).

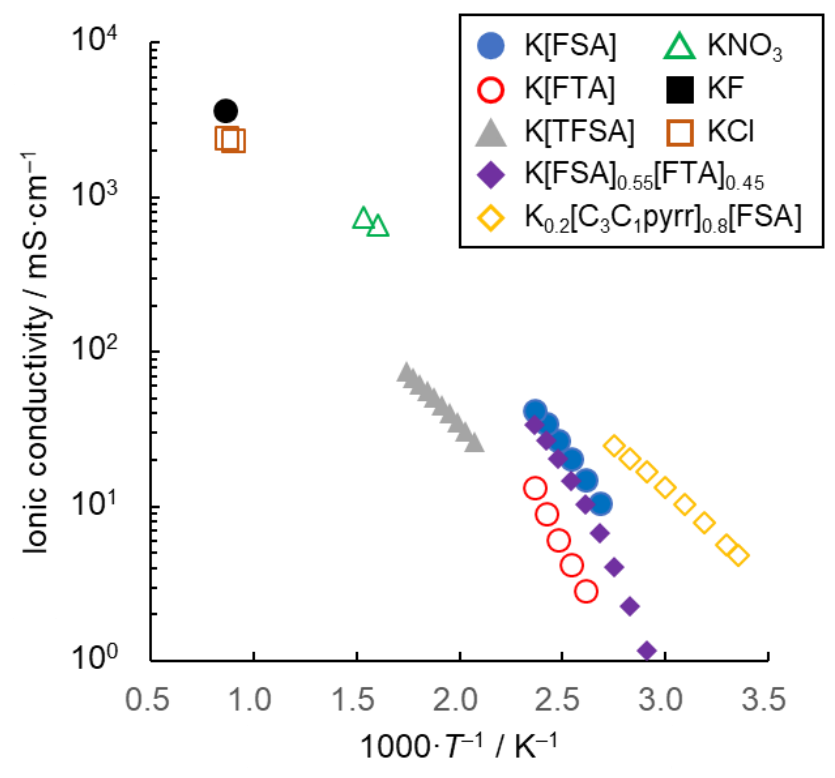

Figure 3. Arrhenius plot for the ionic conductivity of some K-SCILs and RTIL (see references for $\mathrm{KNO}_{3}, \mathrm{KF}, \mathrm{KCl}$, and $\left.\mathrm{K}_{0.2}\left[\mathrm{C}_{3} \mathrm{C}_{1} \mathrm{pyrr}\right]_{0.8}[\mathrm{FSA}]\right) .{ }^{12,32}$ 


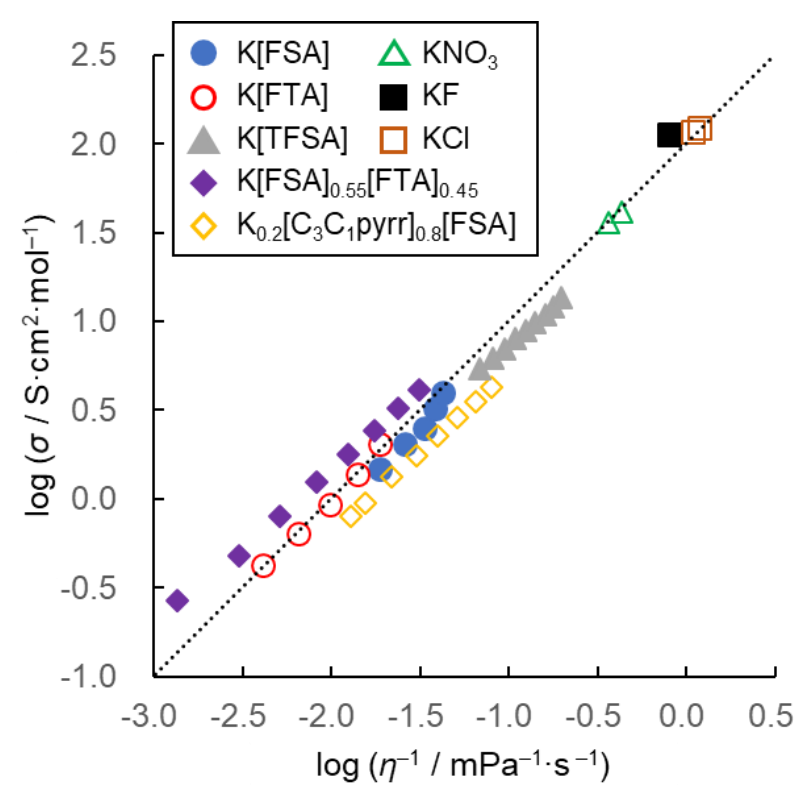

Figure 4. Walden plot for some K-SCILs and RTIL (see references for $\mathrm{KNO}_{3}, \mathrm{KF}, \mathrm{KCl}$, and $\mathrm{K}_{0.2}\left[\mathrm{C}_{3} \mathrm{C}_{1} \text { pyrr }\right]_{0.8}[\mathrm{FSA}]$ ). (see references for $\mathrm{KNO}_{3}, \mathrm{KF}, \mathrm{KCl}$, and $\mathrm{K}_{0.2}\left[\mathrm{C}_{3} \mathrm{C}_{1} \text { pyrr }\right]_{0.8}[\mathrm{FSA}]$ ). ${ }^{12,32}$

3.4. Limiting Current for Partial Potassium Conduction. The ionic conductivity described above is generated by all ions in the K[FSA $]_{0.55}[\mathrm{FTA}]_{0.45} \mathrm{SCIL}$, i.e., $\mathrm{K}^{+}$, FSA ${ }^{-}$and $\mathrm{FTA}^{-}$. As electrolytes for PIBs, the partial conductivity of $\mathrm{K}^{+}$in the $\mathrm{K}-\mathrm{SCIL}$ is the most important parameter because it restricts the rate capability of the target battery. The current limited by the $\mathrm{K}^{+}$partial conductivity (limiting current) in PIBs is defined by the parameters of the electrolyte and electrochemical cell based on the following equation: ${ }^{8,37}$

$$
I_{\mathrm{L}}^{\mathrm{C}}=4 F D c / A d
$$

where $I_{\mathrm{L}}{ }^{\mathrm{C}}$ is the calculated limiting current density ( $\mathrm{C}$ is the calculated value), $F$ is the Faraday constant, $D$ is the diffusion coefficient of $\mathrm{K}^{+}, c$ is the concentration of $\mathrm{K}^{+}, A$ is the area of the working electrode, and $d$ is the distance between the working and counter electrodes. In this study, 
$D$ is not measured directly; however, its maximum value $\left(D^{\mathrm{C}}\right)$ can be estimated from the viscosity using the Stokes-Einstein equation:

$$
D^{\mathrm{C}}=k T / \pi a r \eta
$$

where $k$ is the Boltzmann constant, $r$ is the hydrodynamic radius of an ion-dominating viscosity, and $a$ is a theoretical constant that was empirically obtained between 4 to 6 for the slip and stick boundary conditions, respectively. Table 1 summarizes these parameters for the K-SCIL and RTIL electrolytes in our electrochemical cell. The parameters, $r$ and $a$, were assumed to be the smallest values for obtaining $D^{\mathrm{C}}$, and therefore, the maximum $I_{\mathrm{L}}{ }^{\mathrm{C}}\left(r=0.165 \mathrm{~nm}\right.$ as the ionic radius of $\mathrm{K}^{+}$ and $a=4$ as the slip condition $)^{38}$. The $I_{\mathrm{L}}{ }^{\mathrm{C}}$ of the K[FSA $]_{0.55}[\mathrm{FTA}]_{0.45}$ SCIL electrolyte is lower than that of the $\mathrm{K}_{0.2}\left[\mathrm{C}_{3} \mathrm{C}_{1} \text { pyrr }\right]_{0.8}[\mathrm{FSA}] \mathrm{RTIL}$ electrolyte, which is mainly due to the greater viscosity. However, as shown in Figure 5, the cell voltage for the $\mathrm{K}_{0.2}\left[\mathrm{C}_{3} \mathrm{C}_{1} \text { pyrr }\right]_{0.8}[\mathrm{FSA}] \mathrm{RTIL}$ electrolyte declined rapidly when applying excess current beyond $I_{\mathrm{L}}{ }^{\mathrm{C}}$. This indicates that the diffusion of $\mathrm{K}^{+}$reached its limit due to the concentration gradient; therefore, there was no $\mathrm{K}^{+}$near the working electrode, and the current was then consumed by the decomposition of the organic cation of the RTIL, rather than deposition of potassium metal. However, the K[FSA $]_{0.55}[\mathrm{FTA}]_{0.45}$ SCIL achieved a steady cell voltage under the same conditions, despite its larger overpotential than the RTIL electrolyte. This indicates that a concentration gradient did not occur in the $\mathrm{K}[\mathrm{FSA}]_{0.55}[\mathrm{FTA}]_{0.45}$ SCIL system, and the concentration of $\mathrm{K}^{+}$should be maintained throughout the electrolyte due to the electroneutrality. Although the measurement of the $\mathrm{K}^{+}$ion transference number provides important information on the present transport phenomenon, the large interfacial 
resistance leads to the difficulty its estimation by potentiostatic polarization or very low frequency impedance techniques. Further improvement in analytical techniques is required on this matter.

Table 1. Concentration of shuttle ions, viscosity, and calculated diffusion coefficient and limiting current density for $\mathrm{K}_{0.2}\left[\mathrm{C}_{3} \mathrm{C}_{1} \text { pyrr }\right]_{0.8}[\mathrm{FSA}]$ and $\mathrm{K}[\mathrm{FSA}]_{0.55}[\mathrm{FTA}]_{0.45} \mathrm{ILs}$ at $90^{\circ} \mathrm{C}$.

\begin{tabular}{|c|c|c|c|c|}
\hline Electrolyte & $\begin{array}{c}\mathrm{c} \\
/ \mathbf{m o l} \cdot \mathbf{d m} \mathbf{m}^{-3}\end{array}$ & $\begin{array}{c}\boldsymbol{\eta} \\
/ \mathbf{m P a} \cdot \mathbf{s}\end{array}$ & $\begin{array}{c}D^{\mathrm{C} b} \\
/ \mathbf{1 0}^{-10} \cdot \mathrm{m}^{2} \cdot \mathbf{s}^{-1}\end{array}$ & $\begin{array}{c}I_{\mathbf{L}}^{\mathbf{C} b} \\
/ \mathbf{m A} \cdot \mathbf{c m}^{-2}\end{array}$ \\
\hline $\mathrm{K}_{0.2}\left[\mathrm{C}_{3} \mathrm{C}_{1} \text { pyrr }\right]_{0.8}[\mathrm{FSA}]$ & $0.94^{a}$ & $12.5^{a}$ & 1.93 & 29.1 \\
\hline K[FSA $]_{0.55}[\mathrm{FTA}]_{0.45}$ & 8.5 & 334 & 0.0724 & 8.9 \\
\hline
\end{tabular}

${ }^{a}$ These values were obtained from Ref. 12 .

${ }^{b} D^{\mathrm{C}}$ and $I_{\mathrm{L}}^{\mathrm{C}}$ were calculated by Eqs (3) and (4), assuming $A=0.126 \mathrm{~cm}^{2}$ and $d=0.2 \mathrm{~cm}$.

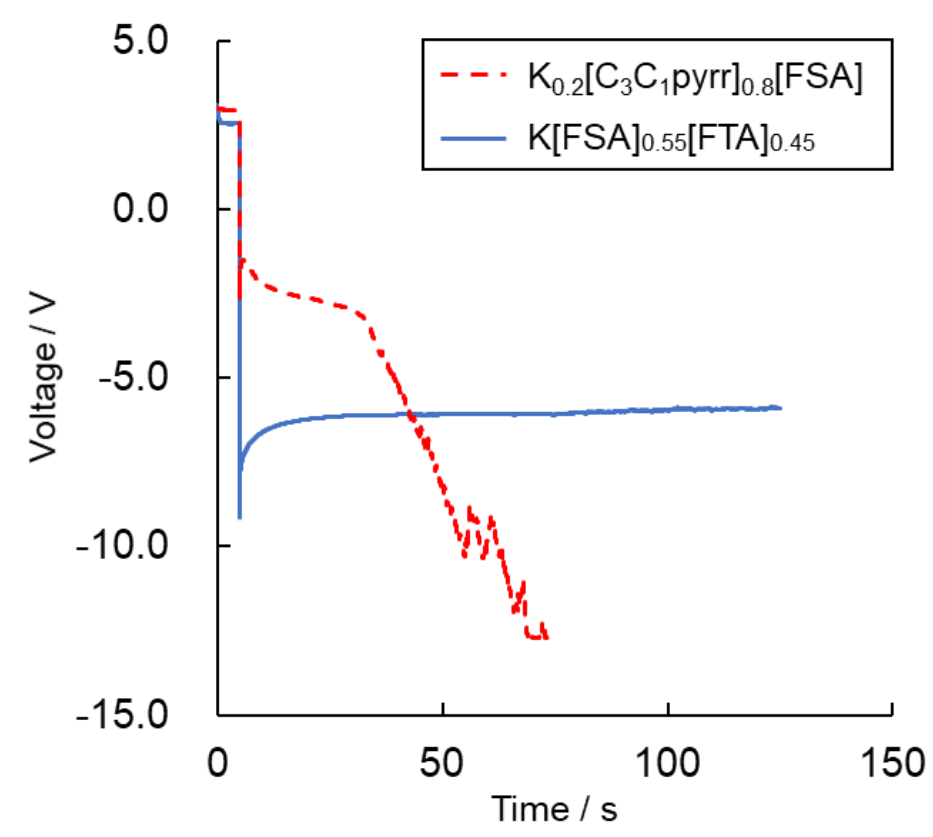

Figure 5. Time-voltage profile of the $\mathrm{K} \| \mathrm{Al}$ cell during galvanostatic polarization at a constant current of $80 \mathrm{~mA} \cdot \mathrm{cm}^{-2}$ at $90{ }^{\circ} \mathrm{C}$. 
3.5. Electrochemical Window. The electrochemical window, which is defined by the limit potentials of the cathode and anode, is one of the main features determining the compatibility of electrode materials. As shown in Figure 6, the cathode and anode limits of the K[FSA $]_{0.55}[\mathrm{FTA}]_{0.45}$ SCIL were measured by cyclic voltammetry in the two-electrode cell with an aluminum or a platinum working electrode, respectively. The cathode limit was $0 \mathrm{~V}$ vs. $\mathrm{K} / \mathrm{K}^{+}$, which corresponds to the reversible deposition and dissolution of potassium metal. The coulombic efficiency was $60 \%$, which could be attributed to the decomposition of the anions or the elimination of the deposited potassium metal from the working electrode at $90{ }^{\circ} \mathrm{C}$ above the melting point of potassium metal $\left(63.5^{\circ} \mathrm{C}\right)$. The anode limit, which was determined when the current density exceeded $0.4 \mathrm{~mA} \cdot \mathrm{cm}^{-2}$, was $5.6 \mathrm{~V}$ vs. $\mathrm{K} / \mathrm{K}^{+}$. This reaction is the oxidative decomposition of $\mathrm{FSA}^{-}$ and/or $\mathrm{FTA}^{-}$anions.

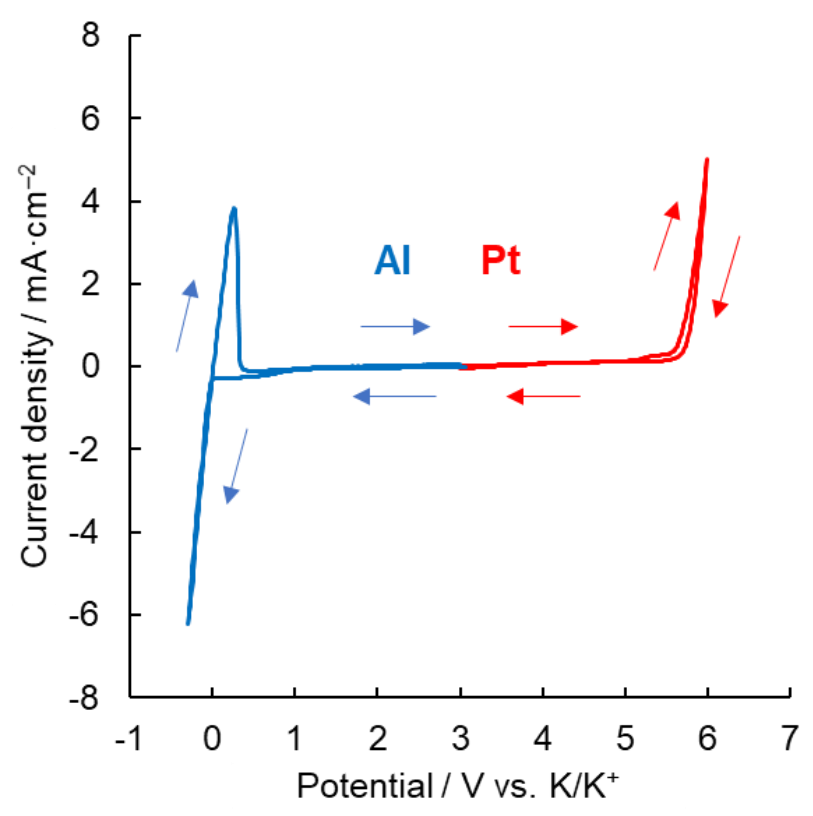

Figure 6. Combined cyclic voltammogram of the K[FSA $]_{0.55}[\mathrm{FTA}]_{0.45} \mathrm{SCIL}$ at a scan rate of 10 $\mathrm{mV} \cdot \mathrm{s}^{-1}$ and $90^{\circ} \mathrm{C}$. 
3.6. Potassium Intercalation into Graphite. Figure 7 shows the charge-discharge curves of the graphite electrode in the $\mathrm{K}[\mathrm{FSA}]_{0.55}[\mathrm{FTA}]_{0.45} \mathrm{SCIL}$ electrolyte at $80^{\circ} \mathrm{C}$. The infrequent spikes are likely due to the insufficient contact of the liquid potassium counter electrode to the current collector. The electrode was charged at a constant current $(\mathrm{CC})$ of $0.3 \mathrm{C}$ below the cut-off voltage of 2.5-0.1 V and constant voltage (CV) at $0.1 \mathrm{~V}$ for cycles, and was discharged at a constant current of $0.3 \mathrm{C}$. The first charge capacity was $640 \mathrm{mAh} \cdot \mathrm{g}^{-1}$, while the theoretical capacity was 279 $\mathrm{mAh} \cdot \mathrm{g}^{-1}$, corresponding to the formation of $\mathrm{KC}_{8}$. This high capacity was derived from the decomposition of $\mathrm{FSA}^{-}$or $\mathrm{FTA}^{-}$to form a solid electrolyte interphase (SEI) film. From the second cycle, the charge capacity decreased as the number of cycles increased, and reached $254 \mathrm{mAh} \cdot \mathrm{g}^{-1}$ at the 50th cycle (Figure S3). However, the discharge capacity of the first cycle was $273 \mathrm{mAh} \cdot \mathrm{g}^{-1}$, which was mostly consistent with the theoretical capacity (over 97\%). The discharge capacity also gradually decreased as the number of cycles increased, and reached $230 \mathrm{mAh} \cdot \mathrm{g}^{-1}$ at the 50 th cycle. This gradual decrease is due to the degradation of the graphite composite electrode, which may be caused by the thermal brittleness of the PVDF binder. The coulombic efficiency of $\mathrm{K}^{+}$ intercalation/deintercalation is approximately $90 \%$ after the 50 th cycle. The $10 \%$ irreversibility indicates that the $\mathrm{FSA}^{-}$or $\mathrm{FTA}^{-}$were continuously decomposed on the electrode at $80{ }^{\circ} \mathrm{C}$. Unstability of SEI can cause this irreversibility, and further study on constituent ion or effective additive is required to improve it.

Figure 8 shows the ex-situ XRD patterns of the graphite electrodes before charging, and after the first charge and discharge. After charging, the peak at $26.62^{\circ}$ corresponding to the 002 diffraction of the pristine graphite disappeared, and new peaks appeared at $16.57^{\circ}$ and $33.55^{\circ}$, corresponding to $d=5.35$ and $2.67 \AA$, respectively. These peaks can be indexed as 001 and 002 
respectively, which provides the interlayer distance of $5.35 \AA$ and the formation of the first-stage potassium-graphite intercalation compound (K-GIC), although the peaks may be indexed as 004 and 008 , respectively, by considering the interlayer arrangements of $\mathrm{K}^{+}$as discussed in previous works. $^{39,40}$ The formation of the first-stage K-GIC was also consistent with its brown-colored appearance after the first charge. ${ }^{41,42}$ The intercalation of $\mathrm{K}^{+}$proceeded fully along with the disappearance of the peak ascribed to the second stage K-GIC (around $20.5^{\circ}$ and $30.1^{\circ}$ ). ${ }^{41,43}$ The weak peak intensity of the charged sample was due to the electrolyte remaining on the electrode without rinsing. The electrode rinsing process, which is typically executed before ex-situ measurements to remove the electrolyte, may affect the GIC electrode chemistry. ${ }^{44,45}$ After discharge, these peaks disappeared and the 002 diffraction peak of graphite recovered at $26.49^{\circ}$ which is almost the same angle as that before charging. This indicates that the intercalation and deintercalation of $\mathrm{K}^{+}$to graphite proceeded reversibly.

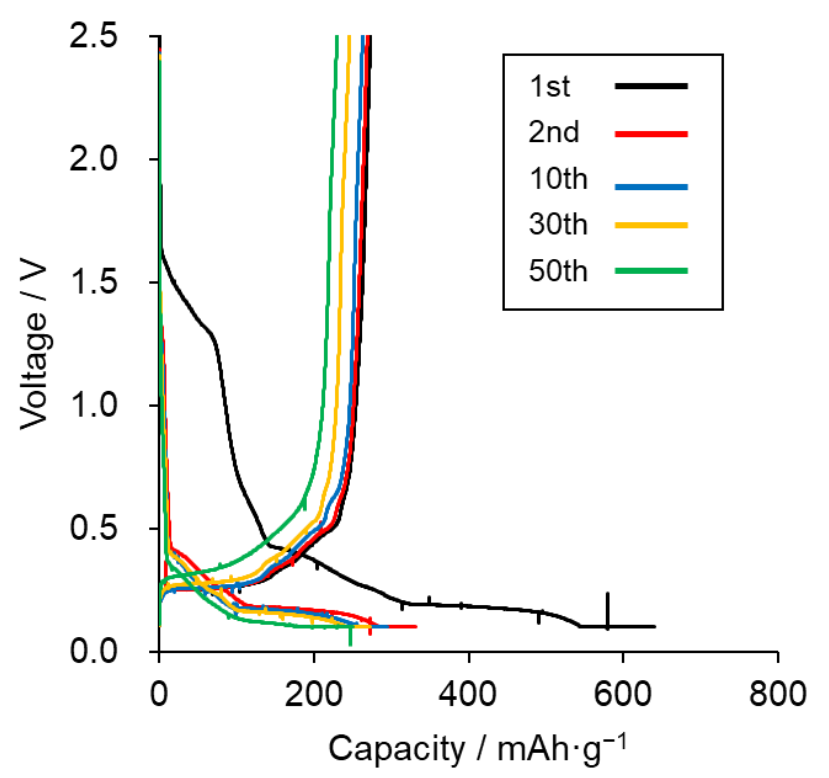

Figure 7. Charge-discharge curves of the K\|graphite cell using the K[FSA $]_{0.55}[\mathrm{FTA}]_{0.45}$ SCIL at a charge/discharge rate of $0.3 \mathrm{C}$ and $80{ }^{\circ} \mathrm{C}$. 


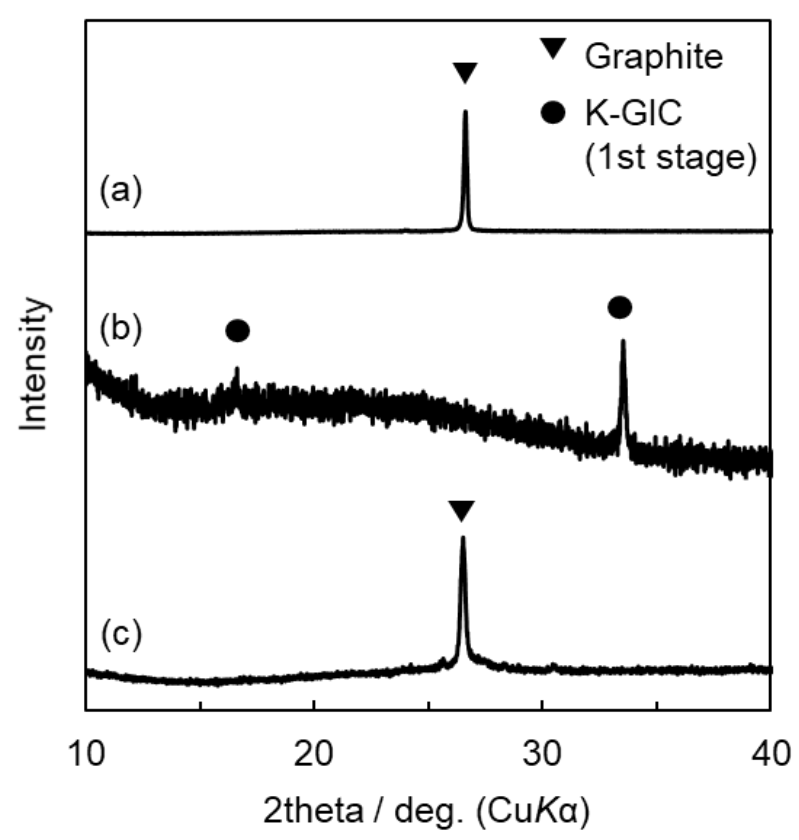

Figure 8. XRD patterns of the graphite electrodes. (a) Before charging, (b) after charging, and (c) after discharge in the K[FSA $]_{0.55}[\mathrm{FTA}]_{0.45}$ SCIL.

\section{CONCLUSIONS}

This study investigated the K-SCIL based on $\mathrm{K}^{+}$as an electrolyte for PIB. The melting point of the K[FSA] and K[FTA] mixture was reduced to $67^{\circ} \mathrm{C}$ at $\mathrm{K}[\mathrm{FSA}]_{0.55}[\mathrm{FTA}]_{0.45}$. The transport properties of this electrolyte were poor when compared to those of room temperature electrolytes containing an organic solvent or RTIL; however, it achieved superionic conductance at elevated temperature under a large current due to the absence of a concentration gradient for $\mathrm{K}^{+}$. The large electrochemical window of over $5 \mathrm{~V}$ for this system is beneficial for application in PIBs. The graphite negative electrode exhibited stable charge and discharge behavior in this K-SCIL, with a discharge capacity near the theoretical value for the formation of $\mathrm{KC}_{8}$. The $\mathrm{K}^{+}$ intercalation/deintercalation into/from graphite were confirmed by ex-situ XRD measurements. 
The thermal and transport properties of the K-SCIL could be improved by the addition of a third potassium salt. The battery tests will be conducted by the combination of some appropriate positive electrode in the future.

\section{ASSOCIATED CONTENT}

\section{Supporting Information}

The Supporting information is available free of charge at $\operatorname{xxxx}$.

Thermal analysis and electrochemical data.

\section{AUTHOR INFORMATION}

\section{Corresponding Author}

Name: Keigo Kubota

E-mail: keigo-kubota@aist.go.jp

Phone: +81-72-751-9047

ORCID: 0000-0002-0536-129X

Name: Kazuhiko Matsumoto

E-mail: k-matsumoto@energy.kyoto-u.ac.jp

Phone: +81-75-753-5827

ORCID: 0000-0002-0770-9210

\section{Co-Author}

Name: Hiroki Yamamoto 
E-mail: yamamoto.hiroki.42u@st.kyoto-u.ac.jp

Phone: +81-75-753-4817

ORCID: 0000-0003-3751-6978

Name: Chih-Yao Chen,

E-mail: chen.chihyao@ aist.go.jp

Phone: +81-72-751-9047

ORCID: 0000-0002-8799-4647

Name: Rika Hagiwara

E-mail: hagiwara@energy.kyoto-u.ac.jp

Phone: +81-75-753-5822

ORCID: 0000-0002-7234-3980

\section{Notes}

The authors declare no competing financial interest.

\section{ACKNOWLEDGEMENTS}

The authors thank National Institutes of Advanced Industrial and Science and Technology (AIST) for financial support. 


\section{REFERENCES}

(1) Tarascon, J. M.; Armand, M. Issues and Challenges Facing Rechargeable Lithium Batteries. Nature 2001, 414, 359-367.

(2) Braun, P. V.; Cho, J.; Pikul, J. H.; King, W. P.; Zhang, H. High Power Rechargeable Batteries. Curr. Opin. Solid State Mater. Sci. 2012, 16, 186-198.

(3) Tarascon, J. M. Is Lithium the New Gold? Nat. Chem. 2010, 2, 510.

(4) Hwang, J. Y.; Myung, S. T.; Sun, Y. K. Recent Progress in Rechargeable Potassium Batteries. Adv. Funct. Mater. 2018, 28, 1802938.

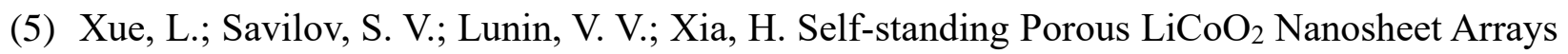
as 3D Cathodes for Flexible Li-ion Batteries. Adv. Funct. Mater. 2018, 28, 1705836.

(6) Yao Z.; Xia, X.; Xie, D.; Wang, Y.; Zhou, C.; Liu, S.; Deng, S.; Wang, X.; Tu, J. Enhancing Ultrafast Lithium Ion Storage of $\mathrm{Li}_{4} \mathrm{Ti}_{5} \mathrm{O}_{12}$ by Tailored TiC/C Core/Shell Skeleton Plus Nitrogen Doping. Adv. Funct. Mater. 2018, 28, 1802756.

(7) Zeng, G.; An, Y.; Fei, H.; Yuan, T.; Qing, S.; Ci, L.; Xiong, S.; Feng, J. Green and Facile Synthesis of Nanosized Polythiophene as an Organic Anode for High-Performance Potassium-Ion Battery. Funct. Mater. Lett. 2018, 11, 1840003.

(8) Bruce, P. G.; Vincent, C. A. Steady State Current Flow in Solid Binary Electrolyte Cells. J. Electroanal. Chem. 1987, 225, 1-17.

(9) Kubota, K.; Tamaki, K.; Nohira; T.; Goto, T.; Hagiwara, R. Electrochemical properties of alkali bis(trifluoromethylsulfonyl)amides and their eutectic mixtures. Electrochim. Acta, 2010, 55, 1113-1119.

(10)Eftekhari, A. Potassium Secondary Cell Based on Prussian Blue Cathode. J. Power Sources 2004, 126, 221-228. 
(11)Zeng, G.; Xiong, S.; Qian, Y.; Ci, L.; Feng, J. Non-Flammable Phosphate Electrolyte with High Salt-to-Solvent Ratios for Safe Potassium-Ion Battery. J. Electrochem. Soc. 2019, 166, A1217-A1222.

(12) Yamamoto, T.; Matsumoto, K.; Hagiwara, R.; Nohira, T. Physicochemical and Electrochemical Properties of $\mathrm{K}\left[\mathrm{N}\left(\mathrm{SO}_{2} \mathrm{~F}\right)_{2}\right]-[\mathrm{N}-$ Methyl-N-propylpyrrolidinium $]\left[\mathrm{N}\left(\mathrm{SO}_{2} \mathrm{~F}\right)_{2}\right]$ Ionic Liquids for Potassium-ion Batteries. J. Phys. Chem. C 2017, 121, 18450-18458.

(13)Masese, T.; Yoshii, K.; Yamaguchi, Y.; Okumura, T.; Huang, Z. D.; Kato, M.; Kubota, K.; Furutani, J.; Orikasa, Y.; Senoh, H.; Sakaebe, H.; Shikano, M. Rechargeable Potassium-ion Batteries with Honeycomb-Layered Tellurates as High Voltage Cathodes and Fast Potassiumion Conductors. Nat. Commun. 2018, 9, 3823-3834.

(14)Fei, H.; Liu, Y.; An, Y.; Xu, X.; Zeng, G.; Tian, Y.; Ci, L.; Xi, B.; Xiong, S.; Feng, J. Stable All-solid-state Potassium Battery Operating at Room Temperature with A Composite Polymer Electrolyte and A Sustainable Organic Cathode. J. Power Sources 2018, 399, 294-298.

(15)Komaba, S.; Hasegawa, T.; Dahbi M.; Kubota, K. Potassium Intercalation into Graphite to Realize High-voltage/high-power Potassium-ion Batteries and Potassium-ion capacitors. Electrochem. Commun. 2015, 60, 172-175.

(16)Okoshi, M.; Yamada, Y.; Komaba, S.; Yamada, A.; Nakai, H. Theoretical Analysis of Interactions between Potassium Ions and Organic Electrolyte Solvents: A Comparison with Lithium, Sodium, and Magnesium Ions. J. Electrochem. Soc. 2017, 164, A54-A60.

(17)Kubota, K.; Dahbi, M.; Hosaka, T.; Kumakura, S.; Komaba, S. Towards K-ion and Na-ion Batteries as "Beyond Li-ion". Chem. Rec. 2018, 18, 459-479.

(18) Morita, M.; Shibata, T.; Yoshimoto, N.; Ishikawa, M. Anodic Behavior of Aluminum in Organic Solutions with Different Electrolytic Salts for Lithium Ion Batteries. Electrochim. 
Acta 2002, 47, 2787-2793.

(19)Bie, X.; Kubota, K.; Hosaka, T.; Chihara, K.; Komaba, S. A Novel K-Ion Battery: Hexacyanoferrate(II)/graphite Cell. J. Mater. Chem. A 2017, 5, 4325-4330.

(20) Yoshida, K.; Nakamura, M.; Kazue, Y.; Tachikawa, N.; Tsuzuki, S.; Seki, S.; Dokko, K.; Watanabe, M. Oxidative-stability Enhancement and Charge Transport Mechanism in Glyme-Lithium Salt Equimolar Complexes. J. Am. Chem. Soc. 2011, 133, 13121-13129.

(21)Suo, L.; Borodin, O.; Gao, T.; Olguin, M.; Ho, J.; Fan, X.; Luo, C.; Wang C.; Xu, K. "Waterin-salt" Electrolyte Enables High-voltage Aqueous Lithium-ion Chemistries. Science 2015, $350,938-943$.

(22)Matsumoto, K.; Inoue, K.; Nakahara, K.; Yuge, R.; Noguchi T.; Utsugi, K. Suppression of Aluminum Corrosion by Using High Concentration LiTFSI Electrolyte. J. Power Sources 2013, 231, 234-238.

(23)Hosaka, T.; Kubota, K.; Kojima, H.; Komaba, S. Highly Concentrated Electrolyte Solutions for 4 V Class Potassium-ion Batteries. Chem. Commun. 2018, 54, 8387-8390.

(24)Shobukawa, H.; Tokuda, H.; Tabata, S.; Watanabe, M. Preparation and Transport Properties of Novel Lithium Ionic Liquids. Electrochim. Acta 2004, 50, 305-309.

(25)Tao, R.; Miyamoto, D.; Aoki, T.; Fujinami, T. Novel Liquid Lithium Borates Characterized with High Lithium Ion Transference Numbers. J. Power Sources 2004, 135, 267-272.

(26) Kubota, K.; Matsumoto, H. Investigation of an Intermediate Temperature Molten Lithium Salt Based on Fluorosulfonyl(trifluoromethylsulfonyl)amide as a Solvent-Free Lithium Battery Electrolyte. J. Phys. Chem. C 2013, 117, 18829-18836.

(27)Beran, M.; Prihoda, J.; Zak, Z.; Cerník, M. A New Route to The Syntheses of Alkali Metal Bis(fluorosulfuryl)imides: Crystal Structure of $\mathrm{LiN}\left(\mathrm{SO}_{2} \mathrm{~F}\right)_{2}$. Polyhedron 2006, 25, 1292-1298. 
(28)Kubota, K.; Nohira, T.; Hagiwara, R.; Matsumoto H. Thermal Properties of Alkali (Fluorosulfonyl)(trifluoromethylsulfonyl)amides. Chem. Lett. 2010, 39, 1303-1304.

(29) Mukai, T.; Nishikawa, K. Syntheses and crystal structures of two ionic liquids with halogenbonding groups: 4,5-dibromo- and 4,5-diiodo-1-butyl-3-methylimidazolium trifluoromethanesulfonates. Solid State Sci. 2010, 12, 783-788.

(30) Matsumoto K.; Oka, T.; Nohira, T.; Hagiwara, R. Polymorphism of Alkali Bis(fluorosulfonyl)amides $\left(\mathrm{M}\left[\mathrm{N}\left(\mathrm{SO}_{2} \mathrm{~F}\right)_{2}\right], \mathrm{M}=\mathrm{Na}, \mathrm{K}\right.$, and $\left.\mathrm{Cs}\right)$. Inorg. Chem. 2013, 52, $568-576$.

(31)Kubota K.; Matsumoto H. Melting and Crystallization Behaviors of Alkali Metal (Fluorosulfonyl)(trifluoromethylsulfonyl)amides. Chem. Lett. 2011, 40, 1105-1106.

(32)Janz, G. J. Thermodynamic and Transport Properties for Molten Salts: Evaluated Density, Surface Tension, Electrical Conductance, and Viscosity Data. J. Phys. Chem. Ref. Data 1988, 17, 1-309.

(33) Kubota, K.; Tamaki, K.; Nohira, T.; Goto, T.; Hagiwara, R. Electrochemical Properties of Alkali Bis(trifluoromethylsulfonyl)amides and Their Eutectic Mixtures. Electrochim. Acta 2010, 55, 1113-1119.

(34) Xu, W.; Cooper, E. I.; Angell, C. A. Ionic Liquids: Ion Mobilities, Glass Temperatures, and Fragilities. J. Phys. Chem. B 2003, 107, 6170-6178.

(35)Walden, P.; Ulich, H.; Busch, G. Conductivity Measurements in Acetone. Z. Phys. Chem. 1926, 123, 429-434.

(36) Yoshizawa, M.; Xu, W.; Angell, C. A. Ionic Liquids by Proton Transfer: Vapor Pressure, Conductivity, and the Relevance of $\Delta \mathrm{pKa}$ from Aqueous Solutions. J. Am. Chem. Soc. 2003, $125,50,15411-15419$. 
(37)Park, J-W.; Yoshida, K.; Tachikawa, N.; Dokko, K.; Watanabe, M. Limiting Current Density in Bis(trifluoromethylsulfonyl)amide-based Ionic Liquid for Lithium Batteries. J. Power Sources 2011, 196, 2264-2268.

(38) Shannon, R. D.; Prewitt, C. T. Effective Ionic Radii in Oxides and Fluorides. Acta Cryst. 1969, B25, 925-946.

(39) Rüdorff, W.; Schulze, E. Über Alkaligraphitverbindungen. Z. Anorg. Chem. 1954, 277, 156-171.

(40)Wang, Z.; Selbach, S. M.; Grande, T. Van der Waals density functional study of the energetics of alkali metal intercalation in graphite. RSC $a d v . \mathbf{2 0 1 4}, 4,4069-4079$.

(41)Komaba, S.; Hasegawa, T.; Dahbi, M.; Kubota, K. Potassium Intercalation into Graphite to Realize High-Voltage/High-Power Potassium-Ion Batteries and Potassium-Ion Capacitors. Electrochem. Commun. 2015, 60, 172-175.

(42)Zhao, J.; Zou, X.; Zhu, Y.; Xu, Y.; Wang, C. Electrochemical Intercalation of Potassium into Graphite. Adv. Funct. Mater. 2016, 26, 8103-8110.

(43)Luo, W.; Wan, J.; Ozdemir, B.; Bao, W.; Chen, Y.; Dai, J., Lin, H.; Xu, Y.; Gu, F.; Barone, V.; Hu, L.; Potassium Ion Batteries with Graphitic Materials. Nano Lett. 2015, 15, 7671-7677.

(44) Jegoudez, J.; Mazieres, C. Behavior of the binary graphite intercalation compounds $\mathrm{KC}_{8}$ and $\mathrm{KC}_{24}$ towards a set of simple organic molecules. Synthetic Met. 1983, 7, 85-91.

(45)Elia, G. A.; Hasa, I.; Greco, G.; Diemant, T.; Marquardt, K.; Hoeppner, K.; Behm, R. J.; Hoell, A.; Passerini, S.; Hahn, R. Insights into the Reversibility of Aluminum Graphite Batteries. J. Mater. Chem. A 2017, 5, 9682-9690. 


\section{TOC Graphic}

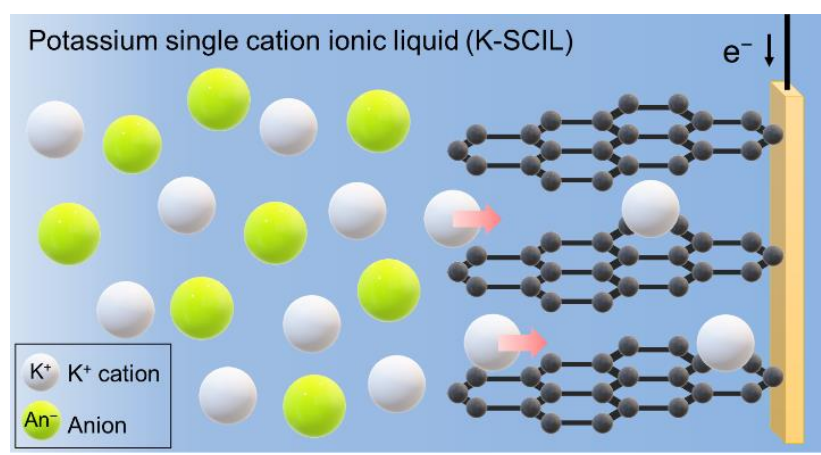

